\title{
Cardiac fibrosis in mice with hypertrophic cardiomyopathy is mediated by non-myocyte proliferation and requires Tgf- $\beta$
}

\begin{abstract}
Polakit Teekakirikul, ${ }^{1}$ Seda Eminaga, ${ }^{1}$ Okan Toka, ${ }^{1,2}$ Ronny Alcalai, ${ }^{1,3}$ Libin Wang, ${ }^{1}$ Hiroko Wakimoto, ${ }^{1,4}$ Matthew Nayor, ${ }^{1}$ Tetsuo Konno, ${ }^{1}$ Joshua M. Gorham, ${ }^{1}$ Cordula M. Wolf, ${ }^{1,4}$ Jae B. Kim, ${ }^{1,5}$ Joachim P. Schmitt,, ${ }^{1,6}$ Jefferey D. Molkentin,, 7,8 Russell A. Norris, ${ }^{9}$ Andrew M. Tager, ${ }^{10}$ Stanley R. Hoffman, ${ }^{9}$ Roger R. Markwald, ${ }^{9}$ Christine E. Seidman, ${ }^{1,5,11}$ and Jonathan G. Seidman ${ }^{1}$

'Department of Genetics, Harvard Medical School, Boston, Massachusetts, USA. ²Department of Pediatric Cardiology, Children's Hospital, University of Erlangen-Nuremberg, Erlangen, Germany. ${ }^{3}$ Heart Institute, Hadassah Hebrew University Medical Center, Jerusalem, Israel. ${ }^{4}$ Department of Cardiology, Children's Hospital Boston, Boston, Massachusetts, USA. ${ }^{5}$ Division of Cardiovascular Medicine, Brigham and Women's Hospital, Boston, Massachusetts, USA. ${ }^{6}$ Institute of Pharmacology and Toxicology, University of Würzburg, Würzburg, Germany. ${ }^{7}$ Department of Pediatrics, University of Cincinnati, Cincinnati Children's Hospital Medical Center, Cincinnati, Ohio, USA. ${ }^{8}$ Howard Hughes Medical Institute, Cincinnati, Ohio, USA. 9Division of Rheumatology/Department of Medicine and Department of Regenerative Medicine and Cell Biology, Medical University of South Carolina, Charleston, South Carolina, USA. ${ }^{10}$ Pulmonary and Critical Care Unit and Center for Immunology and Inflammatory Diseases, Massachusetts General Hospital, Harvard Medical School, Boston, Massachusetts, USA. ${ }^{11}$ Howard Hughes Medical Institute, Boston, Massachusetts, USA.
\end{abstract}

\begin{abstract}
Mutations in sarcomere protein genes can cause hypertrophic cardiomyopathy (HCM), a disorder characterized by myocyte enlargement, fibrosis, and impaired ventricular relaxation. Here, we demonstrate that sarcomere protein gene mutations activate proliferative and profibrotic signals in non-myocyte cells to produce pathologic remodeling in HCM. Gene expression analyses of non-myocyte cells isolated from HCM mouse hearts showed increased levels of RNAs encoding cell-cycle proteins, Tgf- $\beta$, periostin, and other profibrotic proteins. Markedly increased BrdU labeling, Ki67 antigen expression, and periostin immunohistochemistry in the fibrotic regions of HCM hearts confirmed the transcriptional profiling data. Genetic ablation of periostin in HCM mice reduced but did not extinguish non-myocyte proliferation and fibrosis. In contrast, administration of Tgf- $\beta$-neutralizing antibodies abrogated non-myocyte proliferation and fibrosis. Chronic administration of the angiotensin II type 1 receptor antagonist losartan to mutation-positive, hypertrophynegative (prehypertrophic) mice prevented the emergence of hypertrophy, non-myocyte proliferation, and fibrosis. Losartan treatment did not reverse pathologic remodeling of established HCM but did reduce nonmyocyte proliferation. These data define non-myocyte activation of Tgf- $\beta$ signaling as a pivotal mechanism for increased fibrosis in HCM and a potentially important factor contributing to diastolic dysfunction and heart failure. Preemptive pharmacologic inhibition of Tgf- $\beta$ signals warrants study in human patients with sarcomere gene mutations.
\end{abstract}

\section{Introduction}

Dominant mutations in sarcomere protein genes cause hypertrophic cardiomyopathy (HCM), a primary myocardial disorder characterized by myocyte enlargement, increased myocardial fibrosis, and impaired ventricular relaxation that predisposes patients to develop heart failure (1-5). The population incidence of sarcomere protein gene mutations is considerable (4-6), and recent epidemiologic studies document 7 -fold increased risk of heart failure in the 40 million individuals estimated to carry these defects (4). Definition and inhibition of the signals that cause pathologic cardiac remodeling in response to sarcomere protein gene mutations may therefore have broad impact on human health.

Previous studies of HCM mutations in the myosin heavy chain gene showed that these enhance sarcomere biophysical properties (7-9) and alter cardiac relaxation (10) and calcium signaling in myocytes (11), events that are associated with widespread transcriptional

Authorship note: Polakit Teekakirikul, Seda Eminaga, and Okan Toka contributed equally to this work. Christine E. Seidman and Jonathan G. Seidman contributed equally to this work

Conflict of interest: The authors have declared that no conflict of interest exists. Citation for this article: J Clin Invest. 2010;120(10):3520-3529. doi:10.1172/JCI42028. changes (12). In addition to inducing changes within myocytes, the characteristic histopathology found in HCM hearts implies that sarcomere gene mutations also impact non-myocyte cells.

Myocardial fibrosis, the collagen-rich extracellular matrix that is presumed to derive from fibroblast-like cells within the heart is substantially increased in HCM (13-15). Both interstitial fibrosis, which surrounds individual myocytes, and focal fibrosis, the microscopic scars that replace dead myocytes, accrue in HCM. Increased myocardial fibrosis is maladaptive, and accumulation correlates with impaired cardiac relaxation (16) and increases the propensity for heart failure. Mechanisms by which myocyte-specific mutations in sarcomere protein genes increase myocardial fibrosis remain unknown.

To define profibrotic signals in HCM, we studied 2 mouse lines that carry different human mutations in the $\alpha$-cardiac myosin heavy chain gene: Arg403Gln (referred to as $\alpha-\mathrm{MHC}^{403 /+}$ ) (17) and $\operatorname{Arg} 719 \operatorname{Trp}$ (referred to as $\alpha-\mathrm{MHC}^{719 /+}$; Supplemental Figure 1; supplemental material available online with this article; doi:10.1172/ JCI42028DS1). These mice exhibit protean manifestations of HCM, including hypertrophy and focal fibrosis in adulthood $(17,18)$. The hearts from young $\alpha-\mathrm{MHC}^{403 /+}$ and $\alpha-\mathrm{MHC}^{719 /+}$ mice, like human children with HCM mutations, have normal 
A
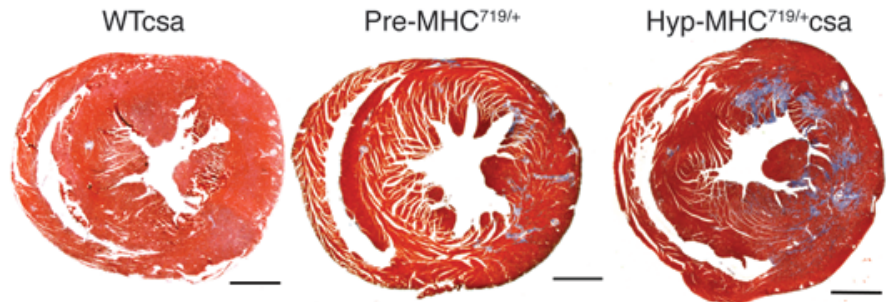

B

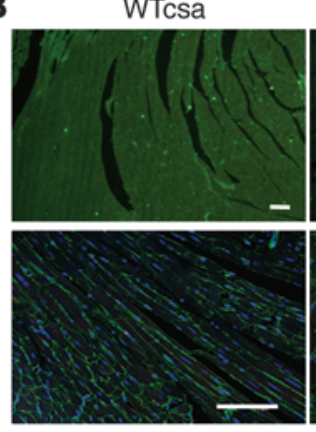

Hyp-MHC ${ }^{719 /+}$ csa

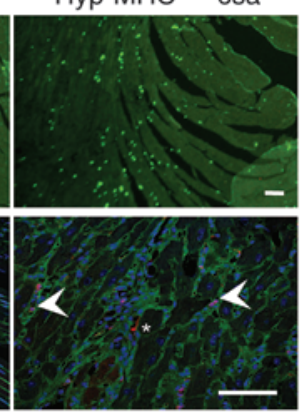

C

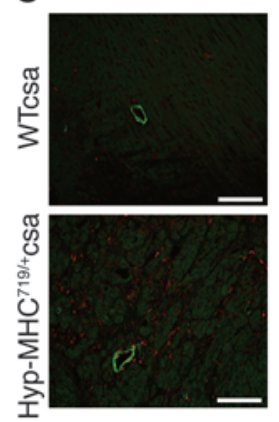

\section{Figure 1}

Hypertrophic $\alpha-\mathrm{MHC}^{719 /+}$ mice have cardiac hypertrophy, increased myocardial fibrosis, and non-myocyte cell proliferation. (A) Masson trichrome-stained sections from prehypertrophic (Pre-) and hypertrophic (Hyp-) $\alpha-\mathrm{MHC}^{719 /+} \mathrm{csa}$ hearts revealed increased fibrosis (blue) in comparison with WTcsa hearts. Scale bar: $1 \mathrm{~mm}$. (B) Light microscopy shows increased BrdU incorporation in sections from $\alpha-\mathrm{MHC}^{719 /+} \mathrm{Csa}$ hearts (top panel, original magnification, $\times 50$ ). Confocal immunofluorescence after WGA (green), DAPI (blue) stains, and BrdU antibodies revealed proliferating non-myocyte cells (magenta nuclei, arrowheads) in regions with increased fibrosis (bottom panel, original magnification, $\times 400)$. There was minor nonspecific antibody staining $\left({ }^{*}\right)$ outside the nuclei. In comparison with WTcsa heart sections, note that $\alpha-\mathrm{MHC}^{719 /+} \mathrm{csa}$ hearts have disorganized myocardial architecture. Scale bar: $75 \mu \mathrm{m}$. (C) Confocal immunofluorescence shows expression of $\alpha$-smooth muscle actin and fibroblastspecific protein 1 (Fsp1/S100a4), detected using a FITC-conjugated $\alpha$-smooth muscle actin mouse antibody (green) and S100a4 antibody (red), respectively. Note that FITC-conjugated $\alpha$-smooth muscle actin labeled only vascular beds in WTcsa and hypertrophic $\alpha-\mathrm{MHC}^{719 /+} \mathrm{c}$ csa hearts. Scale bar: $75 \mu \mathrm{m}$.

dimensions and histology throughout a period of clinical latency (denoted as prehypertrophic). Despite the absence of hypertrophy or HCM histopathology, our studies of RNA expression in LV tissues from prehypertrophic $\alpha$-MHC ${ }^{403 /+}$ mouse hearts (12) demonstrated increased transcription of genes associated with fibrosis.

To characterize molecular signals that promote fibrosis in $\alpha-\mathrm{MHC}^{403 /+}$ and $\alpha-\mathrm{MHC}^{719 /+}$ mice, we used comprehensive transcriptional analyses of RNAs expressed in isolated myocytes and non-myocyte cells from prehypertrophic HCM hearts and from hearts with overt HCM. Guided by increased expression of RNAs in non-myocyte cells, we assessed cell proliferation in HCM hearts and targeted potential signaling molecules implicated in activating fibrosis in HCM. Using these data, we tested and report a pharmacologic strategy for extinguishing the emergence of pathologic remodeling in prehypertrophic HCM mice.

\section{Results}

HCM models. We studied 2 mouse HCM models. We used the previously described $\alpha$-MHC $\mathrm{M}^{403 /+}$ mice $(17,18)$, and we produced what we believe to be a new model that carries the Arg719Trp mutation in the $\alpha$-cardiac myosin heavy chain gene ( $\alpha$-MHC ${ }^{719 /+}$ mice), using homologous recombination technology (Supplemental Figure 1). Hearts from young ( $<20$ weeks) $\alpha-\mathrm{MHC}^{719 /+}$ mice, like those of juvenile $\alpha$-MHC ${ }^{403 /+}$ mice, do not have LV hypertrophy or HCM histopathology and are designated prehypertrophic. By 35 weeks, $\alpha-\mathrm{MHC}^{719 /+}$ mice exhibit both hypertrophy and HCM histopathology that is indistinguishable from that of adult $\alpha-\mathrm{MHC}^{403 /+}$ mice.

Our prior studies (11) showed that cyclosporine A (CsA) administration to young $\alpha-\mathrm{MHC}^{403 /+}$ mice accelerates the emergence of HCM (referred to as hypertrophic $\alpha-\mathrm{MHC}^{403 /{ }^{+} \mathrm{csa}}$ mice). CsA-treated WT mice (WTcsa mice) develop neither hypertrophy nor histopathology. CsA-treated $\alpha-\mathrm{MHC}^{719 /+}$ mice (referred to as hypertrophic $\alpha-\mathrm{MHC}^{719 /+}$ csa mice) showed accelerated development of increased LV wall thickness (LVWT), overt HCM histopathology, including increased myocardial fibrosis, and preserved cardiac function (Figure $1 \mathrm{~A}$ and Table 1). The maximum LVWT was 1.8-fold increased in hypertrophic $\alpha-\mathrm{MHC}^{719 /{ }^{+} \mathrm{cs}}$ mice compared with that of WTcsa mice $\left(P=3 \times 10^{-4}\right)$. Masson trichrome-stained sections showed approximately 80 -fold greater fibrosis in hearts ( $n=3$ per genotype) from hypertrophic $\alpha-\mathrm{MHC}^{719 /{ }^{+}} \mathrm{csa}$ mice than WTcsa mice $(4.4 \% \pm 2.8 \%$ vs. $0.05 \% \pm 0.07 \%$, $n \geq 27$ sections per genotype; $P=1.3 \times 10^{-11}$ ) and $40 \%$ more cardiac fibrosis than prehypertrophic $\alpha-\mathrm{MHC}^{719 /+}$ mice $(n=7 ; 3.10 \% \pm 3.1 \% ; n \geq 105$ sections per genotype; $P=0.012$; Figure $1 \mathrm{~A})$.

RNA profiles of isolated cardiac myocytes and non-myocyte cells. To define signaling pathways that promote fibrosis in response to a sarcomere gene mutation, RNA expression was assessed by deep sequence analysis of gene expression (DSAGE; see Methods) in myocytes and nonmyocyte cells isolated from hearts of 9- to 12-week-old WT, prehypertrophic $\alpha$-MHC ${ }^{403 /+}$, WTcsa, and hypertrophic $\alpha-\mathrm{MHC}^{403 /+} \mathrm{csa}$ mice. Of 15,579 distinct RNAs found in non-myocyte cells, 7,578 RNAs were expressed at higher levels than in myocytes. Among RNAs that were significantly enriched in non-myocyte cells $(P<0.001), 1,317$ changed with hypertrophic remodeling (Supplemental Table 1); expression decreased in 272 RNAs and increased in 1,045 RNAs. Non-myocyte RNAs that were significantly increased $(P<0.0001)$ in hypertrophic $\alpha-\mathrm{MHC}^{403 /{ }^{+} \mathrm{cs} a}$ mice compared with WTcsa mice (Supplemental Tables 1 and 2) included transcripts encoding extracellular matrix proteins that have been previously identified in fibroblasts from other tissues, such as periostin (Postn), Tgfb, connective tissue growth factor (Ctgf), collagens (19), vimentin, chemokines (20), and metalloproteinases (21).

Using the DAVID (version 6.7) $(22,23)$ functional annotation tool, we identified 18 Gene Ontology (GO) terms (Supplemental Table 3) that were significantly overrepresented $(P<0.05$ after Bonferroni correction) among differentially expressed genes in non-myocyte cells (Supplemental Table 1). This unbiased analysis corroborated our interpretation of DSAGE data, in that GO terms related to extracellular matrix, cell-cycle control, and cell proliferation were enriched in non-myocyte cell RNAs (Supplemental Table 3). Notably, 50 RNAs encoding proteins involved in cell-cycle control had significantly altered levels $(P=0.01$ after Bonferroni correction; see bolded RNAs in Supplemental Tables 1 and 3). Based upon these transcriptional profiles, we concluded that non-myocyte cells in hypertrophic $\alpha-\mathrm{MHC}^{403 /{ }^{+} \mathrm{csa}}$ hearts were activated. 


\section{Table 1}

Effects of Tgf- $\beta$ inhibition or periostin ablation on cardiac morphology and function in HCM mice

\begin{tabular}{|c|c|c|c|c|c|c|c|c|}
\hline Genotype & Treatment $^{A}$ & No. of mice & LVWTmax (mm) & $P$ value & $\operatorname{LVDD}(\mathrm{mm})$ & $P$ value & FS (\%) & $P$ value \\
\hline WTcsa & None & 5 & $0.73 \pm 0.13$ & & $3.64 \pm 0.20$ & & $38.79 \pm 7.46$ & \\
\hline$\alpha-\mathrm{MHC}^{719 /+} \mathrm{csa}$ & None & 4 & $1.33 \pm 0.17$ & $3 \times 10^{-4}$ & $2.90 \pm 0.19$ & $8 \times 10^{-4}$ & $37.29 \pm 5.77$ & NS \\
\hline$\alpha-\mathrm{MHC}^{719 /+} \mathrm{Csa}$ & Losartan & 3 & $0.64 \pm 0.03$ & NS $\left(7 \times 10^{-4}\right)^{B}$ & $3.63 \pm 0.37$ & NS $(0.018)^{B}$ & $32.85 \pm 5.21$ & $\mathrm{NS}(\mathrm{NS})^{\mathrm{B}}$ \\
\hline$\alpha-\mathrm{MHC}^{719 /+} \mathrm{csa}$ & $\mathrm{Rb} \lg \mathrm{G}$ & 4 & $1.19 \pm 0.20$ & 0.004 & $3.22 \pm 0.46$ & NS & $36.61 \pm 4.82$ & NS \\
\hline$\alpha-\mathrm{MHC}^{719 /+} \mathrm{csa}$ & Tgf- $\beta$ NAb & 4 & $0.77 \pm 0.10$ & NS $(0.009)^{\mathrm{C}}$ & $3.48 \pm 0.10$ & NS $(N S)^{C}$ & $33.65 \pm 2.79$ & NS $(N S)^{c}$ \\
\hline Postn ${ }^{-1}$ csa & None & 5 & $0.7 \pm 0.05$ & NS & $3.44 \pm 0.31$ & NS & $41.47 \pm 5.23$ & NS \\
\hline$\alpha-\mathrm{MHC}^{403 /+} \mathrm{Csa}$ & None & 6 & $1.21 \pm 0.27$ & 0.006 & $3.38 \pm 0.31$ & NS & $40.99 \pm 5.59$ & NS \\
\hline Postn ${ }^{-/} \alpha-\mathrm{MHC}{ }^{403 /+} \mathrm{csa}$ & None & 5 & $0.97 \pm 0.37$ & $\mathrm{NS}(\mathrm{NS})^{\mathrm{D}}$ & $3.22 \pm 0.51$ & $\mathrm{NS}(\mathrm{NS})^{\mathrm{D}}$ & $43.16 \pm 6.61$ & NS (NS) \\
\hline
\end{tabular}

AAll mice received CsA plus the indicated antibody or drug. $P$ values reflect comparison with WTcsa mice. Additional comparisons are shown in parentheses: Blosartan-treated $\alpha-\mathrm{MHC}{ }^{719 /+}$ csa mice versus untreated $\alpha-\mathrm{MHC}{ }^{719 /+}$ csa mice; ${ }^{\mathrm{C}}$ Tgf- $\beta$ NAb-treated $\alpha-\mathrm{MHC}{ }^{719 /+}$ Csa mice versus IgG-treated $\alpha-\mathrm{MHC}{ }^{719 /}$

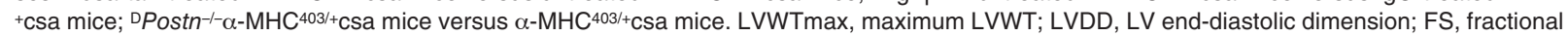
shortening at the diastole.

Proliferation and characterization of activated non-myocyte cells. To obtain in vivo confirmation of activated pathways in non-myocyte cells during hypertrophic remodeling, we assessed cell proliferation in $\alpha-\mathrm{MHC}^{403 /{ }^{+}} \mathrm{csa}$ and $\alpha-\mathrm{MHC}^{719 /+}$ csa mice, using incorporation of BrdU to detect newly synthesized DNA and nuclear expression of Ki67 to detect cell-cycle activity $(20,24,25)$. BrdU was injected 3 days prior to sacrifice of hypertrophic mice and sections were stained with BrdU and Ki67 antibodies (Figure 1B; see Methods). Results from these independent methodologies were concordant, but as expected, absolute numbers of Ki67 antigen-labeled cells were consistently lower than those of BrdU-labeled cells. As in other studies $(26,27)$, we found no evidence for myocyte proliferation; BrdU and Ki67 antibodies labeled only non-myocyte cells.

There were 4-fold more BrdU-labeled non-myocyte cells from hypertrophic $\alpha-\mathrm{MHC}^{719 /{ }^{+}} \mathrm{csa} \mathrm{LV}$ sections than from prehypertrophic or WTcsa LV sections $\left(P=3 \times 10^{-12}\right)$. In regions with normal histologic architecture (e.g., absence of focal fibrosis or expansion of the interstitium) from WTcsa and prehypertrophic $\alpha-\mathrm{MHC}^{719 /+}$ mice, amounts of BrdU-labeled non-myocyte cells were similar $(0.10 \%-0.14 \%,>155,000$ cells per genotype), but these were 3.3 -fold increased in hypertrophic $\alpha-\mathrm{MHC}^{719 /+}$ csa mice $(0.42 \% \pm 0.33 \%$, $>97,000$ cells; $\left.P=3 \times 10^{-8}\right)$. In LV sections with focal fibrosis or overt interstitial expansion (identified by wheat germ agglutinin [WGA]) from hypertrophic $\alpha-\mathrm{MHC}^{719 /{ }^{+}} \mathrm{csa}$ mice, BrdU labeled $1.8 \% \pm 1.6 \%$ of non-myocyte cells (>110,000 cells), indicative of 4-fold greater regional proliferation of cells (Figure 1B).

We confirmed that non-myocyte proliferation in hypertrophic hearts from $\alpha-\mathrm{MHC}^{719 /+}$ mice (age >35 weeks) that did not receive CsA. Ki67 antigen labeled $1.1 \% \pm 0.56 \%$ of non-myocyte cells in regions with focal fibrosis and expanded interstitium (identified by WGA) compared with $0.61 \% \pm 0.34 \%$ of non-myocyte cells in regions where the myocardial architecture was preserved $(n=3$ mice, $>19,000$ cells per group; $P=0.001$ ).

Proteinsinvolved in the fibroticresponseto sarcomereprotein gene mutations. Expression of $\alpha$-smooth muscle actin and fibroblast-specific protein (Fsp1, also known as S100a4), encoded by Acta2 and S100a4, respectively, is associated with some fibroblast populations (28-30). We used antibodies to these proteins (Figure 1C) to study hearts from hypertrophic $\alpha-\mathrm{MHC}^{719 /{ }^{+}} \mathrm{csa}$ and WTcsa mice. The $\alpha$-smooth muscle actin antibody stained perivascular smooth muscle cells but not the non-myocyte cells residing throughout the LV. In contrast, Fsp1 antibody labeled few non-myocyte cells in WTcsa hearts but substantial numbers of non-myocyte cells in hypertrophic $\alpha-\mathrm{MHC}^{719 /+}$ csa LV sections, particularly in fibrotic regions in which $28 \%$ of proliferating cells were Fsp 1 positive (Supplemental Figure 2).

Multiple RNAs that encode molecules involved in extracellular matrix biology were enriched in non-myocyte cells isolated from

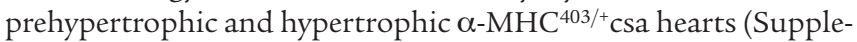
mental Table 1). Among the genes that had the most significantly increased expression ( $\geq 7$ fold) in non-myocyte cells from hypertrophic $\alpha-\mathrm{MHC}^{403 /{ }^{+}}$csa hearts, we identified several Tgf- $\beta$-responsive genes (Supplemental Table 2, indicated in bold), including Postn (periostin). We confirmed increased periostin protein levels by Western blots of LV extracts. Periostin levels in extracts from prehypertrophic $\alpha-\mathrm{MHC}^{719 /{ }^{+}} \mathrm{csa}$, WT, and WTcsa mice were low (Figure 2A), but levels were markedly higher among age-matched hypertrophic $\alpha-\mathrm{MHC}^{719 /+} \mathrm{csa}$ mice. The amount of increase in periostin protein was variable among hypertrophic $\alpha-\mathrm{MHC}^{719 /+} \mathrm{csa} \mathrm{LV}$ extracts, a finding that is consistent with our earlier evidence that fibrotic load differs among identical HCM mice (18).

To determine whether periostin was essential for pathologic remodeling in $\mathrm{HCM}$, we used a genetic strategy. $\alpha-\mathrm{MHC}^{403 /+}$ mice were crossed with periostin-null mice (Postn ${ }^{-1}$ mice ) (31), hypertrophy was induced with CsA, and compound mutant mice were studied by echocardiography and histopathology. WTcsa and Postn ${ }^{-1-} \mathrm{csa}$ mouse ( $n=5$ per genotype) hearts were indistinguishable, with comparable maximal LVWT, normal cardiac histology, and very little fibrosis (Figure 2B). Maximal LVWT was modestly but not significantly reduced in hypertrophic Postn $n^{-/-} \alpha-\mathrm{MHC}^{403 /+} \mathrm{csa}$ mice $(0.97 \pm 0.37 \mathrm{~mm})$ compared with that of hypertrophic $\alpha-\mathrm{MHC}^{403 /{ }^{+}}$csa mice $(1.21 \pm 0.27 \mathrm{~mm}$; Table 1$)$. Masson trichromestained LV sections (Figure $2 \mathrm{~B}$ ) showed less myocardial fibrosis in hypertrophic Postn ${ }^{-/} \alpha-\mathrm{MHC}^{403 /+}$ csa hearts $(2.06 \% \pm 2.0 \%, n=5)$ than hypertrophic $\alpha-\mathrm{MHC}^{403 /{ }^{+}}$csa hearts $(3.12 \% \pm 3.38 \%, n=6$; $P=0.03 ; n>57$ sections per genotype).

To determine whether periostin ablation altered non-myocyte proliferation in HCM hearts, we immunostained heart sections for nuclear Ki67 antigen (Figure 2C). Within fibrotic foci, periostin ablation reduced the number of Ki67-positive non-myocyte cells by 2.4 -fold (hypertrophic Postn ${ }^{-/-} \alpha-\mathrm{MHC}^{403 /+}$ csa mice, $0.55 \% \pm 0.5 \% ; n>125,000$ cells vs. hypertrophic $\alpha-\mathrm{MHC}^{403 /+}$ csa mice, $1.33 \% \pm 0.6 \% ; n>150,000$ cells; $\left.P=6 \times 10^{-14}\right)$. However, the fraction of Ki67-positive nuclei in the LV of Postn ${ }^{-/} \alpha-\mathrm{MHC}^{403 /{ }^{+}} \mathrm{csa}$ mice $(0.33 \% \pm 0.27 \% ; n>235,000$ cells $)$ remained significantly elevated over that of control specimens (WTcsa, $0.05 \% \pm 0.09 \%$; $n>96,000$ cells; 

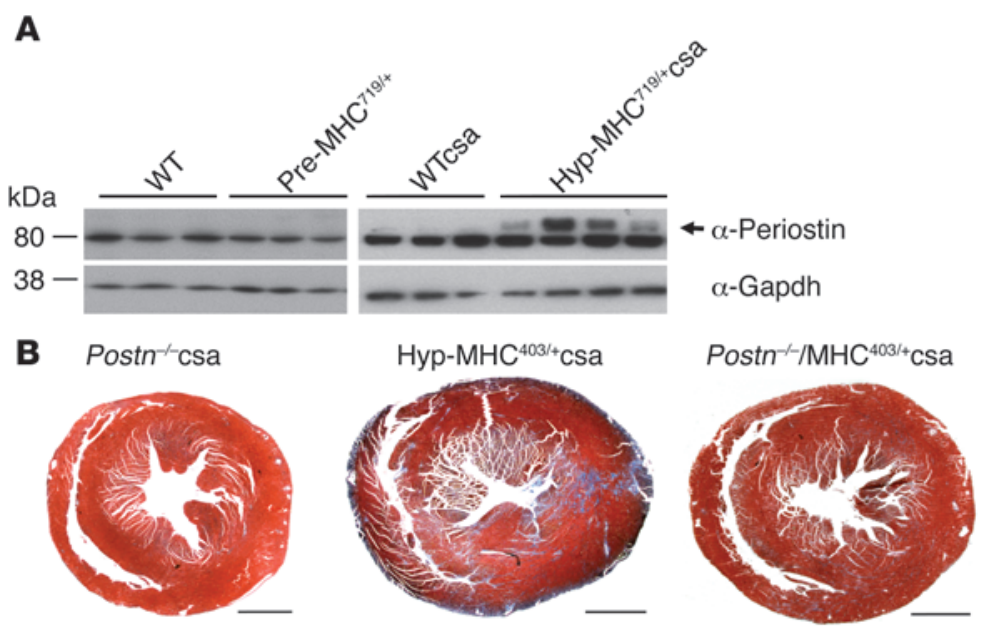

C

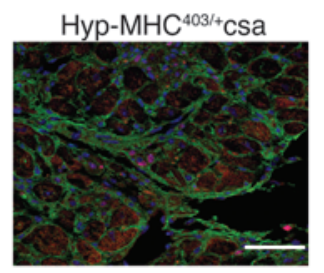

Postn ${ }^{-/} / \mathrm{MHC}^{403 /+} \mathrm{Csa}$

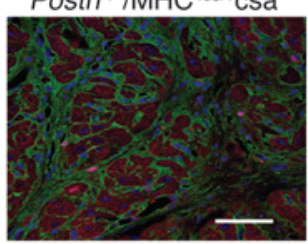

\section{Figure 2}

Increased periostin protein in hypertrophic $\alpha-\mathrm{MHC}^{403 /+}$ and $\alpha-\mathrm{MHC}^{719 /+}$ mice. (A) Western blots detected periostin protein (arrow) in LV extracts from WT, prehypertrophic $\alpha-\mathrm{MHC}^{719 /+}$, WTcsa, and hypertrophic $\alpha-\mathrm{MHC}^{719 /+}$ csa mice but not in extracts from Postn ${ }^{-1-}$ mice (data not shown). Gapdh served as a control for loading. Periostin levels were variable in hypertrophic $\alpha-\mathrm{MHC}^{719 /+}$ csa mice, but densitometry indicated significant increases $(P=0.035)$ above levels in WTcsa mice. (B) Histopathological comparison of fibrotic regions in hearts from Postn ${ }^{-1-}$ csa, hypertrophic $\alpha-\mathrm{MHC}^{403 /+} \mathrm{Csa}$, and Postn ${ }^{-/} \alpha-\mathrm{MHC}^{403 /+}$ csa mice. Scale bar: $1 \mathrm{~mm}$. (C) Immunofluorescent images of LV sections stained for Ki67 antigen (magenta) and DAPI (blue) indicated proliferating cells in fibrotic areas (identified by WGA, green). Scale bar: $75 \mu \mathrm{m}$. Numbers of Ki67 antigen-positive nuclei in fibrotic regions of $\mathrm{Postn}^{-/-} \alpha-\mathrm{MHC}^{403 /{ }^{+} \mathrm{Cs}}$ mice were significantly less than those in $\alpha-\mathrm{MHC}^{403 /+}$ csa mice.
$P=3.4 \times 10^{-43} ;$ Post $^{-/-}$csa, $0.06 \% \pm 0.11 \% ; n>98,000$ cells; $P=3 \times 10^{-45}$ ). Based upon cardiac imaging, histopathology, and non-myocyte proliferation in periostin-null hypertrophic mice, we concluded that periostin contributed to, but was not essential for, pathologic remodeling in HCM.

To address the roles of Tgf- $\beta$ signaling in HCM, we administered Tgf- $\beta$-neutralizing antibodies (Tgf- $\beta$ NAbs) or rabbit IgG prior to and throughout CsA treatment of $\alpha-\mathrm{MHC}^{719 /+}$ mice. The maximum LVWT of Tgf- $\beta$ NAb-treated $\alpha-\mathrm{MHC}^{719 /+}$ csa mice $(0.77 \pm 0.1 \mathrm{~mm})$ was significantly less than that of IgG-treated hypertrophic $\alpha-\mathrm{MHC}^{719 /{ }^{+}}$csa mice $(1.19 \pm 0.2 \mathrm{~mm} ; P=0.009$; Table 1$)$.

There was also significantly less cardiac fibrosis in histological sections from Tgf- $\beta$ NAb-treated mice than in those from IgGtreated hypertrophic $\alpha-\mathrm{MHC}^{719 /+}$ csa mice $(n=4$ per treatment group; Figure 3A). Fibrosis areas encompassed $0.38 \% \pm 0.4 \%$ of LV sections in Tgf- $\beta$ NAb-treated $\alpha-\mathrm{MHC}^{719 /+}$ csa hearts compared with $1.77 \% \pm 1.8 \%$ in IgG-treated hypertrophic $\alpha-\mathrm{MHC}^{719 /{ }^{+}} \mathrm{csa}$ hearts $\left(n=60\right.$ sections per treatment group; $\left.P=4 \times 10^{-8}\right)$. Immunohistochemical staining showed that mice treated with Tgf- $\beta$ NAb but not rabbit IgG, had reduced periostin expression in hypertrophic LV sections (Figure $3 \mathrm{~B}$ ). Moreover, Tgf- $\beta$ NAb-treated $\alpha-\mathrm{MHC}^{719 /+}$ csa mice had significantly less $\left(P=1.7 \times 10^{-10}\right)$ nonmyocyte proliferation (BrdU labeling assessed in $>120,000$ cells per treatment group; Figure $3 \mathrm{C})$ in regions with fibrosis $(0.66 \% \pm 0.06 \%)$ and regions with preserved myocardial architecture $(0.13 \% \pm 0.01 \%)$ as compared with IgG-treated mice (fibrosis, $1.87 \% \pm 0.17 \%$; preserved architecture, $0.62 \% \pm 0.05 \%$ ). Taken together, Tgf- $\beta$ NAb attenuated hypertrophy, abrogated periostin expression, and reduced non-myocyte proliferation in HCM mice.

To identify downstream mediators of Tgf- $\beta$ signaling in HCM, we assessed the location and phosphorylation of Smad2 (pSmad2) in LV sections from mice ( $n=3$ per genotype) (Supplemental Methods). Nuclear pSmad2 was found both in non-myocyte cells and myocytes in $\alpha-\mathrm{MHC}^{719 /+}$ csa $\mathrm{LV}$ sections. Immunohistochemistry (Supplemental Figure 3$)$ detected approximately $50 \%\left(P=9.7 \times 10^{-174}\right)$ more non-myocyte nuclei stained with anti-phosphorylated Smad2 (pSmad2-Ser465/467) in regions with fibrosis $(73.2 \% \pm 14.6 \%$, $>7,500$ cells) as compared with regions with normal myocardial architecture $(48.4 \% \pm 15.9 \%,>6,400$ cells). Based on these data, we deduced that HCM mutations activated the canonical Tgf- $\beta$ signaling pathway in non-myocyte cells.

We extended these studies by harnessing a pharmacologic approach to inhibiting Tgf- $\beta$ signals. Recent data demonstrate that angiotensin II promotes cardiac fibrosis in part by activating Tgf- $\beta$ signals (32). Moreover, the angiotensin II type I receptor antagonist losartan has had salutary effects on animal models of human diseases, including CsA-induced nephropathy (33), Marfan syndrome (34), skeletal myopathies (35), and transgenic overexpression of a cardiac troponin T mutation (36). To assess the effects of losartan in $\mathrm{HCM}$, we treated prehypertrophic $\alpha-\mathrm{MHC}^{719 /+}$ mice for 2 weeks prior to and during CsA induction of HCM. There was no significant difference in the conscious blood pressures of CsA-treated $\alpha-\mathrm{MHC}^{719 /+}$ mice, with or without losartan $(0.44 \mathrm{mg} / \mathrm{d} ; P=\mathrm{NS}$; data not shown). However, the maximum LVWT (Table 1) of losartantreated $\alpha-\mathrm{MHC}^{719 /{ }^{+}}$csa mice $(0.64 \pm 0.03 \mathrm{~mm})$ was comparable with that of WTcsa mice $(0.73 \pm 0.13 \mathrm{~mm} ; P=\mathrm{NS})$ and significantly less $\left(P=7 \times 10^{-4}\right)$ than that of untreated hypertrophic $\alpha-\mathrm{MHC}^{719 /+} \mathrm{csa}$ mice $(1.33 \pm 0.17 \mathrm{~mm})$. Compared with untreated hypertrophic $\alpha-\mathrm{MHC}^{719 /{ }^{+}} \mathrm{csa}$ mice $(n=4)$, losartan-treated $\alpha-\mathrm{MHC}^{719 /+}$ csa mice $(n=3)$ also had 2.9-fold less fibrosis in LV sections $(5.27 \% \pm 0.17 \%$ vs. $1.80 \% \pm 0.19 \%, n \geq 45$ sections per group; $P=1 \times 10^{-24}$; Figure $4 \mathrm{~A}$ ). Consistent with the results of Tgf- $\beta$ NAb studies, periostin expression was substantially reduced in losartan-treated $\alpha-\mathrm{MHC}^{719 /+} \mathrm{csa}$ mice (data not shown). Losartan also inhibited non-myocyte proliferation (Figure 4B). Fewer Ki67-positive non-myocyte cells were observed in losartan-treated mice versus untreated $\alpha-\mathrm{MHC}^{719 /{ }^{+}} \mathrm{csa}$ mice, both in fibrotic regions (treated, $0.14 \% \pm 0.12 \%,>69,000$ cells; untreated, $0.86 \% \pm 0.6 \%,>120,000$ cells; $P=5 \times 10^{-12}$ ) and in regions with preserved myocardial architecture (treated, $0.04 \% \pm 0.06 \%$; $>79,000$ cells; untreated, $0.19 \% \pm 0.25 \%$; > 79,000 cells; $P=2 \times 10^{-4}$ ). 
A

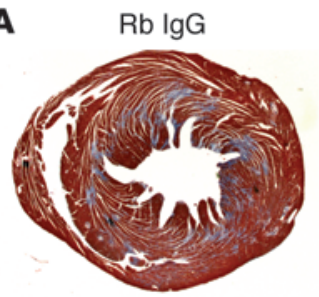

B
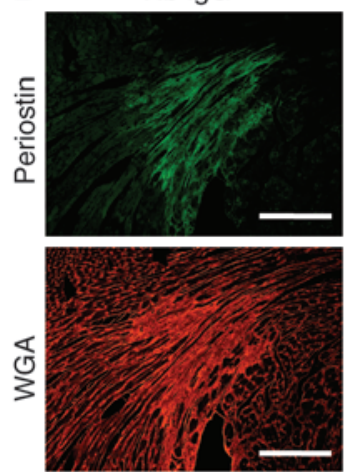
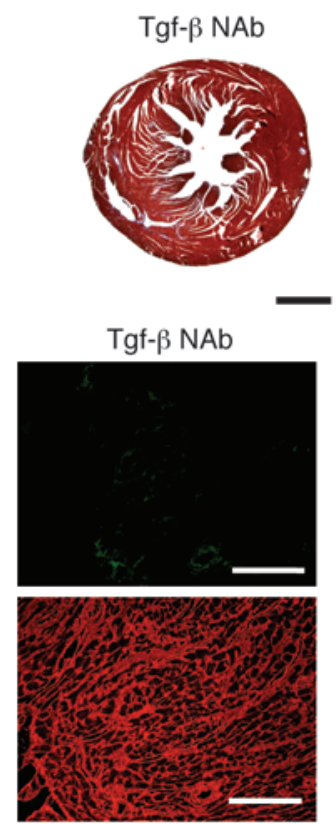

C
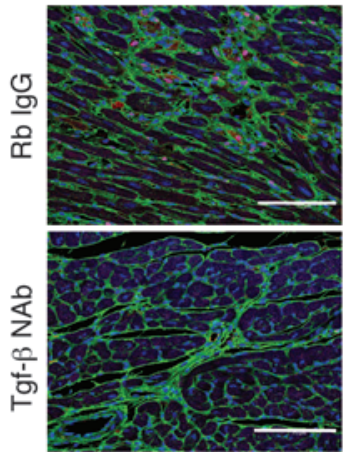

\section{Figure 3}

Tgf- $\beta$ NAb attenuated cardiac fibrosis, reduced periostin expression, and diminished non-myocyte proliferation in hypertrophic $\alpha-\mathrm{MHC}^{719 /+} \mathrm{Csa}$ mice. (A) Histopathologic sections of Tgf- $\beta$ $\mathrm{NAb}$-treated and rabbit $(\mathrm{Rb})$ IgG-treated $\alpha-\mathrm{MHC}^{719 /+}$ csa mice stained with Masson trichrome (blue) demonstrated less fibrosis in Tgf- $\beta$ NAb-treated mice. Scale bar: $1 \mathrm{~mm}$. (B) Immunofluorescent images of LV sections stained for periostin (green) and WGA (red) showed reduced periostin expression in Tgf- $\beta$ $\mathrm{NAb}-$ treated $\alpha-\mathrm{MHC}^{719 /+}$ mice and smaller areas of fibrosis compared with rabbit-IgG treated mice. Scale bar: $0.5 \mathrm{~mm}$. (C) Confocal immunofluorescent images of LV sections from BrdU-treated mice, analyzed using BrdU antibodies (magenta), WGA (green), and DAPI (blue), showed that Tgf- $\beta$ NAb treatment reduced the numbers of proliferating cells in fibrotic areas. Scale bar: $75 \mu \mathrm{m}$.
To determine whether losartan could attenuate the insidious pathologic remodeling that naturally emerges in $\alpha-\mathrm{MHC}^{719 /+}$ mice after 30 weeks (without CsA), we chronically treated prehypertrophic $\alpha-\mathrm{MHC}^{719 /+}$ mice with losartan, beginning at 5 weeks of age. Untreated $\alpha$-MHC ${ }^{719 /+}$ mice developed hypertrophy by 30 weeks of age (maximal LVWT, $1.13 \pm 0.02 \mathrm{~mm}$; Table 2). In contrast, long-term losartan-treated $\alpha-\mathrm{MHC}^{719 /+}$ mice had cardiac dimensions (maximal LVWT, $0.90 \pm 0.02 \mathrm{~mm} ; P=2 \times 10^{-10}$; Table 2 ) that were indistinguishable from those of WT mice (maximal LVWT, $0.89 \pm 0.02 \mathrm{~mm}$ ). Histopathological analysis (Figure 4C) showed little fibrosis in chronic losartan-treated $\alpha-\mathrm{MHC}^{719 /+}$ mice $(0.34 \% \pm 0.04 \%$, $n=7$ mice, 105 sections) in comparison with untreated 35 -week-old $\alpha-\mathrm{MHC}^{719 /+}$ mice $(1.34 \% \pm 0.52 \%, n=10$ mice, 150 sections $)$.

We then asked whether losartan could reverse established hypertrophy and fibrosis in hypertrophic $\alpha-\mathrm{MHC}^{719 /{ }^{+}} \mathrm{csa}$ mice. Nine- to fourteen-week-old hypertrophic $\alpha-\mathrm{MHC}^{719 /+} \operatorname{csa}$ mice $(n=4$, CsA treatment for 3-4 weeks) were treated with a high dosage of losartan $(2.4 \mathrm{mg} / \mathrm{d}$; see Methods) for 4 weeks and compared with untreated age-matched $\alpha-\mathrm{MHC}^{719 /+} \operatorname{csa}(n=4)$ and WTcsa $(n=5)$ mice. The area of fibrosis in $\mathrm{LV}$ sections from losartan-treated mice did not differ from that of hypertrophic $\alpha-\mathrm{MHC}^{719 /{ }^{+}}$csa hearts (treated, $10.99 \% \pm 4.08 \%$; untreated, $10.18 \% \pm 5.59 \% ; n \geq 60$ sections per group; $P=\mathrm{NS}$; Figure $5 \mathrm{~A}$ and data not shown). However, the percentage of BrdU-positive nuclei (Figure 5B) in fibrotic regions from untreated mice $(3.27 \% \pm 3.65 \% ; n>100,000$ cells) was 8 -fold greater than that in fibrotic regions of losartan-treated hearts $(0.41 \% \pm 0.24 \% ; n>100,000$ cells; $\left.P=1.4 \times 10^{-7}\right)$. Losartan treatment reduced the percentage of BrdUpositive nuclei in hypertrophic $\alpha-\mathrm{MHC}^{719 /+} \mathrm{csa}$ hearts $(0.28 \% \pm 0.16 \%$; $n>200,000$ cells $)$ to levels found in WTcsa hearts $(0.27 \% \pm 0.17 \%$; $n>130,000$ cells; $P=\mathrm{NS}$ ).

\section{Discussion}

We demonstrate that myocyte expression of sarcomere protein mutations alters gene transcription in non-myocyte cells, inducing proliferation and expression of profibrotic molecules that produce pathologic remodeling in HCM. Tgf- $\beta$ signals are essential to activating non-myocyte cells: inhibition of these signals, directly by Tgf- $\beta$ NAbs or indirectly by the angiotensin II type 1 receptor antagonist losartan, ameliorated hypertrophy and HCM histopathology in mice. These data indicate a potential therapeutic strategy for patients with sarcomere protein gene mutations.

Amounts of myocardial fibrosis in human HCM hearts correlate with the degree of hypertrophy (37), diminished ventricular performance (38), diastolic dysfunction (16), and energy demands (39) - factors that contribute to heart failure and may increase arrhythmic risk $(40,41)$. As such, the benefit from inhibiting fibrosis in HCM could be substantial.

Fibrosis accrues in HCM hearts due to premature death of mutant myocytes and expansion of the interstitial matrix. Compromised coronary flow due to hypertrophy, microvascular dysfunction (42), increased oxidative stress (43), and increased metabolic demands imposed by abnormal biophysical properties of mutant sarcomeres $(7,8)$ are factors that contribute to premature myocyte death and the emergence of focal fibrosis in HCM. Far less is known about mechanisms that expand the extracellular matrix in HCM hearts. We demonstrated 4- and 3-fold increased non-myocyte proliferation in fibrotic regions (with focal scarring and/or expanded interstitium) and in areas of preserved myocardial architecture, respectively, in overt HCM compared with prehypertrophic $\alpha-\mathrm{MHC}^{719 /+}$ hearts. Although we used a pharmacologic strategy to accelerate the emergence of HCM, the very low proliferation rates of non-myocyte cells in CsA-treated WT mice excluded the likelihood that increased cell division was a drug-induced, mutation-independent response. Instead, we suggest that there is insidious proliferation of non-myocyte cells in untreated HCM mice and human patients. Moreover, transcriptional profiling of non-myocyte cells indicated that proliferation was coupled to increased expression of profibrotic molecules (including collagens, periostin, elastin; Supplemental Table 2), a sequence that could readily expand the extracellular matrix in HCM hearts (Figure 6) and contribute to the progressive diminution of diastolic function observed in human HCM (44). 
A

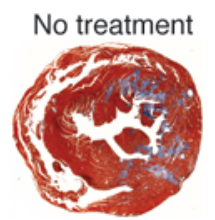

B

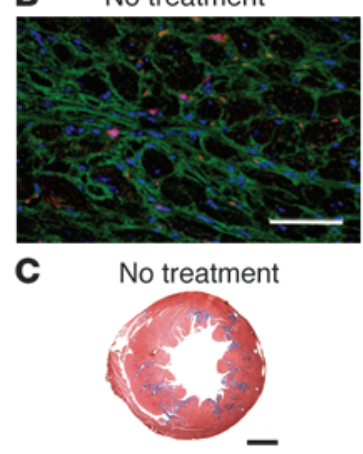

Losartan
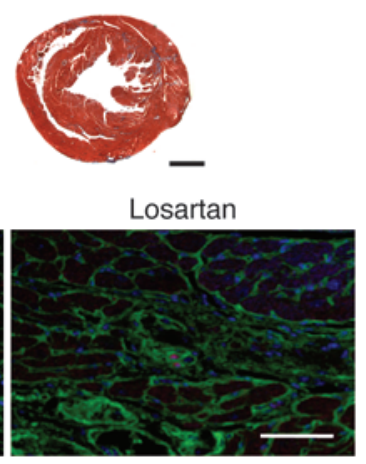

Losartan

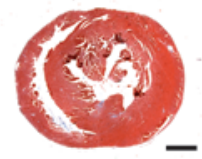

Our studies did not address whether resident or newly recruited cells become activated in HCM. Tgf- $\beta$ signals can stimulate cardiac microvascular endothelial cells to undergo endothelialto-mesenchymal transformation, with migration into the myocardium and expression of genes such as Acta2 (14) and Fsp1 (45). Fsp1 but not $\alpha$-smooth muscle actin was found in non-myocyte cells from hypertrophic hearts (Figure 1C). Activated non-myocyte cells may also be derived from circulating cells (14, 46-48). Alternatively, the enhanced biomechanical forces resulting from sarcomere protein mutations $(7,8)$ could also provide a local mechanism for activating resident non-myocyte cells. Lineage studies are underway to assess the source of activated non-myocyte cells in HCM hearts.

We identified periostin and Tgf- $\beta$ as potentially critical molecules to non-myocyte activation. Periostin has been previously proposed to enable myocyte reentry into the cell cycle (49); however, like others (26), we found no evidence for myocyte proliferation, despite periostin expression in HCM hearts. Periostin also promotes differentiation of circulating cells into cardiac fibroblasts (50), stimulates production of collagen and extracellular matrix production (51), and promotes myocardial healing and scar formation after injury $(31,52)$. These functions might be presumed to be beneficial in HCM, given premature death of mutant myocytes. However, genetic ablation of periostin from HCM mice had no deleterious consequences on survival or cardiac dimensions, despite significantly reducing non-myocyte proliferation in fibrotic foci. Moreover proliferation indices in Postn ${ }^{-/-} \alpha-\mathrm{MHC}^{403 /+} \mathrm{HCM}$ mice were still significantly higher than those in Postn-/- mice, suggesting the involvement of other molecules in non-myocyte proliferation and activation in HCM hearts. This conclusion is supported

\section{Figure 4}

Losartan attenuated cardiac fibrosis, reduced periostin expression, and diminished non-myocyte proliferation in hypertrophic $\alpha-\mathrm{MHC}{ }^{719 /+} \mathrm{csa}$ mice. (A) Histopathologic sections stained with Masson trichrome stain (blue) revealed minimal fibrosis in losartan-treated $\alpha-\mathrm{MHC}^{719 /+} \mathrm{csa}$ compared with untreated $\alpha-\mathrm{MHC}^{719 /+}$ csa mice. Scale bar: $1 \mathrm{~mm}$. (B) Confocal immunofluorescence images of LV sections stained for Ki67 antigen (magenta), WGA (green), and DAPI (blue) showed that losartan reduced non-myocyte proliferation. Scale bar: $60.6 \mu \mathrm{m}$. (C) Cardiac sections stained with Masson trichrome after chronic (30 weeks) losartan treatment in $\alpha-\mathrm{MHC}^{719 /+}$ mice showed markedly reduced amounts of myocardial fibrosis compared with untreated age-matched $\alpha-\mathrm{MHC}^{719 /+}$ mice. Note that these 35-week-old $\alpha-\mathrm{MHC}^{719 /+}$ mice did not receive CsA. Scale bar: $1 \mathrm{~mm}$.

by studies of Postn ${ }^{-/-}$mice subjected to pressure overload, which still developed fibrosis and hypertrophy, albeit more slowly than pressure-overloaded WT mice (31).

In contrast to periostin, we identified Tgf- $\beta$ signals as critical for pathologic remodeling in HCM. Transcript levels of Tgf- $\beta$ were increased in both prehypertrophic and hypertrophic hearts. Treatment of HCM mice with Tgf- $\beta$ NAb extinguished non-myocyte proliferation (Tgf- $\beta$ NAb-treated, $0.13 \% \pm 0.01 \%$; WT, $0.10 \%-0.14 \%$ ), markedly diminished expression of the pro-fibroblast differentiation molecule periostin (Figure 3), and attenuated the emergence LV hypertrophy. Notably, the decrease in non-myocyte proliferation or periostin expression in Tgf- $\beta$ NAb-treated HCM hearts had no adverse impact on LV morphology (e.g., LV wall thinning or ventricular dilatation) or on systolic function (Table 1).

The source of increased Tgf- $\beta$ in HCM hearts may be myocytes or non-myocyte cells. Prehypertrophic myocytes had lower levels of Tgf- $\beta$ transcripts than non-myocyte cells (data not shown) and may reflect some contamination of non-myocyte cells in isolated myocyte preparations (estimated as $<10 \%$ by immunohistochemical studies). Alternatively, modest expression of myocyte Tgf- $\beta$ might occur in response to enhanced biophysical properties of mutant sarcomeres (8), similar to increased Tgf- $\beta$ expression that occurs in cultured WT myocytes subjected to mechanical stretching (53). Biophysical forces of HCM hearts could similarly account for increased Tgf- $\beta$ expression in nonmyocyte cells, as has been observed when non-myocyte cardiac cells are stretched ex vivo $(54,55)$.

In the lung and skin, fibrotic remodeling occurs from activation of latent Tgf- $\beta$ in the extracellular matrix, rather than from increased transcription (56). Mechanical forces can activate latent Tgf- $\beta$, in part through $\alpha v$-containing integrins (57), which respond to local cell-environment interactions. While our studies did not directly address this mechanism for increased Tgf- $\beta$ signaling in HCM, we note that transcriptional profiling (Supplemental Table 1) showed enriched expression of $\alpha v$-containing integrins in non-myocyte cells of the heart and increased expres-

Table 2

Effect of chronic losartan on the emergence of $\mathrm{HCM}$ in $\alpha-\mathrm{MHC}^{719 /+}$ mice

\begin{tabular}{|c|c|c|c|c|c|c|c|c|}
\hline Genotype & Treatment $^{A}$ & No. of mice & LVWT (mm) & $P$ value (vs. WT control) & LVDD (mm) & $P$ value & FS (\%) & $P$ value \\
\hline WT & None & 6 & $0.89 \pm 0.02$ & & $2.74 \pm 0.10$ & & $67 \pm 4$ & \\
\hline$\alpha-\mathrm{MHC}^{719 /+}$ & None & 10 & $1.13 \pm 0.02$ & $5.12 \times 10^{-10}$ & $2.82 \pm 0.11$ & NS & $62 \pm 3$ & NS \\
\hline$\alpha-\mathrm{MHC}^{719 /+}$ & Losartan & 7 & $0.90 \pm 0.02$ & NS & $2.93 \pm 0.26$ & NS & $60 \pm 6$ & NS \\
\hline
\end{tabular}

ALosartan was added to water (110 mg/l); estimated intake was $0.44 \mathrm{mg} / \mathrm{d} / \mathrm{mouse} . P$ values reflect comparison with WT. 

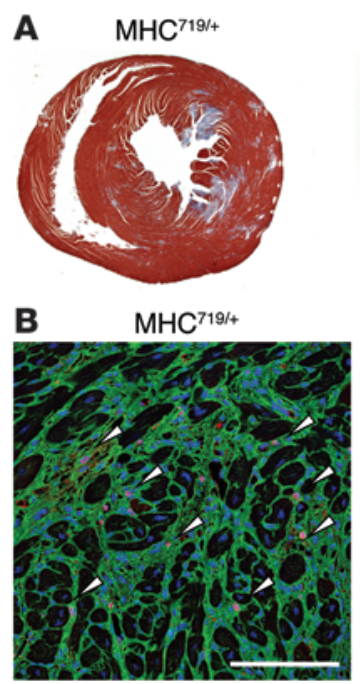

sion of these during hypertrophic remodeling. As such, we suspect that both increased Tgf- $\beta$ transcription and activation contribute to pathologic remodeling in HCM.

Tgf- $\beta$ signaling activates a canonical, Smad-dependent pathway as well as Smad-independent pathways (58). We found heterogeneous nuclear accumulation of pSmad2 in HCM (Supplemental Figure 3 ) occurring in regions with focal fibrosis and expanded interstitial matrix to a greater extent than in regions with preserved myocardial architecture. Similar activation of the canonical Tgf- $\beta$ signaling has been reported in Marfan syndrome (34), inherited muscular dystrophy (35), and autosomal recessive cutis laxa type I (59).

The angiotensin II type 1 receptor inhibitor losartan can limit Tgf- $\beta$ activation (60) and reduce circulating Tgf- $\beta$ (61). In our studies, losartan like Tgf- $\beta$ NAb prevented activation of profibrotic pathways in CsA-accelerated HCM (Figure 4A) and also prevented the spontaneous hypertrophic remodeling that gradually emerges with age in untreated mutant mice (Figure 4C). Although losartan failed to reverse hypertrophy or fibrosis in established HCM (Figure 5), it did reduce numbers of proliferating non-myocyte cells. Ongoing studies will determine whether longer treatment is more beneficial.

Collectively, these data define a mechanism by which sarcomere mutations increase myocardial fibrosis and hypertrophy in HCM through increased expression of Tgf- $\beta$ and activation of the canonical signaling pathway, leading to proliferation of non-myocyte cells and expression of profibrotic molecules (Figure 6). We suggest that

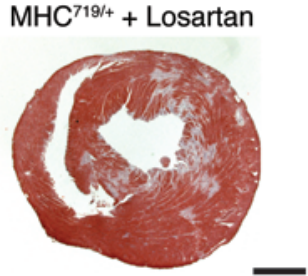

$\mathrm{MHC}^{719 /+}+$ Losartan

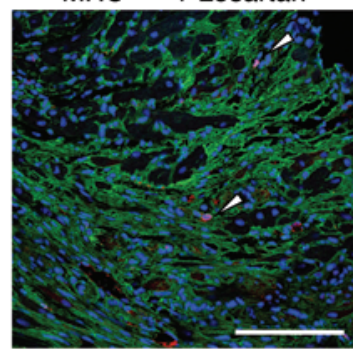

\section{Figure 5}

Losartan did not reverse fibrotic remodeling in established HCM but diminished non-myocyte proliferation. (A) Cardiac sections from hypertrophic $\alpha-\mathrm{MHC}^{719 /{ }^{+}} \mathrm{cs}$ a mice, treated or not treated with losartan, stained with Masson trichrome showed comparable amounts of myocardial fibrosis. Scale bar: $1 \mathrm{~mm}$. (B) Non-myocyte proliferation, assessed by BrdU incorporation, was significantly reduced by losartan treatment compared with that of untreated mice in regions of fibrosis (WGA, green; DAPI, blue). Arrowheads indicate BrdU-positive nuclei. Scale bar: $75 \mu \mathrm{m}$.

this mechanism implicates Tgf- $\beta$ signaling in progressive diastolic dysfunction, the fundamental hemodynamic abnormality observed in HCM that accounts for patient symptoms and outcomes. Whether suppression of Tgf- $\beta$ activation in HCM hearts will attenuate relaxation abnormalities remains an important question.

While these mouse models do not perfectly mimic human disease, our results indicate a new strategy for limiting HCM pathophysiology, early inhibition of Tgf- $\beta$ signaling. With the availability of robust platforms for detecting HCM mutations, identification of individuals with sarcomere protein gene mutations without overt disease and preemptive reduction of Tgf- $\beta$ activation is feasible and may improve outcomes in HCM. We suggest that study of this strategy is warranted.

\section{Methods}

Mouse models. All mice were maintained and studied using protocols approved by the Animal Care and Use Committee of Harvard Medical School. Studies used male heterozygous $\alpha-\mathrm{MHC}^{403 /+}$ or $\alpha-\mathrm{MHC}^{719 /+}$ mice that are in the $129 / \mathrm{SvJ}$ background. $\alpha$-MHC ${ }^{403 /+}$ mice have been extensively characterized $(17,18) . \alpha-\mathrm{MHC}^{719 /+}$ mice were generated by homologous recombination as previously described $(17,62,63)$.
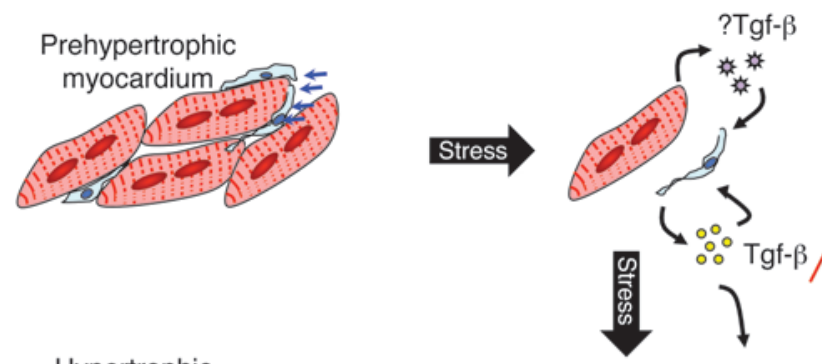

Myocyte

rignals

- (mechanical or chemical)

- Fibrotic
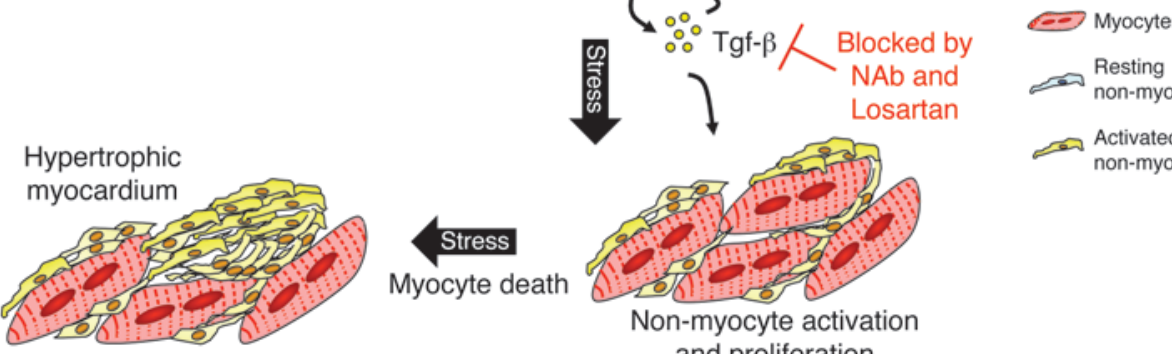

Focal and

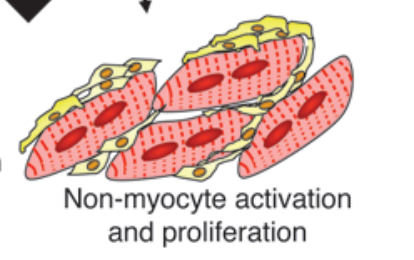
Blocked by

Resting

non-myocyte

Activated non-myocyte
Myocyte death

Non-myocyte activation and proliferation

\section{Figure 6}

A model for increasing fibrosis and diastolic dysfunction from $\mathrm{HCM}$ sarcomere gene mutations. Mutant myocytes have increased biophysical properties (8) and abnormal $\mathrm{Ca}^{2+}$ homeostasis (11), factors that trigger mechanical and/or biochemical signals that activate gene transcription, including increased Tgf- $\beta$ expression. Whether by paracrine and/or autocrine signaling, Tgf- $\beta$ stimulates non-myocyte proliferation and expression of profibrotic molecules. Activated non-myocyte cells secrete profibrotic molecules that expand the interstitium, increase stresses imposed on mutant myocytes, and promote myocyte death with resultant focal scarring. Tgf- $\beta$-mediated increased interstitial and focal fibrosis contributes to diastolic dysfunction in $\mathrm{HCM}$ hearts. Preemptive antagonism of Tgf- $\beta$ signaling by a neutralizing antibody (NAb) or losartan reduces non-myocyte proliferation and profibrotic gene expression, thereby limiting cardiac fibrosis. 
Hypertrophic remodeling was accelerated in prehypertrophic $\alpha$-MHC $\mathrm{C}^{403 /+}$ or $\alpha-\mathrm{MHC}^{719 /+}$ mice (age $6-10$ weeks) by subcutaneous injection of CsA $(15 \mathrm{mg} / \mathrm{kg}$ body weight in PBS, twice daily) for $2-5$ weeks. For all CsA studies, control mice were age-matched, male CsA-treated WT mice.

Post $n^{-/-}$mice are in the $129 / \mathrm{SvEv}$ background and have been previously described $(31,51,64)$. Postn ${ }^{-/} \alpha-M H C^{403 /+}$ mice, generated by mating, were genotyped by PCR amplification and restriction enzyme digestion of genomic DNA $(17,31)$.

Mouse blood pressure measurement and echocardiography. Blood pressure was measured in conscious mice, as described previously (11). Echocardiograms were performed under $2.0 \%$ isoflurane anesthesia, using a Vevo 770 High-Resolution In Vivo Micro-Imaging System and RMV 707B Scanhead (VisualSonics Inc.), by 2 experienced researchers, without knowledge of mouse genotypes. Measurements of left parasternal long and short axes and M-mode (left parasternal short axis) images were obtained at a heart rate of 500-550 bpm, as described previously (18). LV end-diastolic diameter (LVEDD), LV end-systolic diameter (LVESD), and wall thickness were measured from M-mode tracings, and the average of 3 consecutive cardiac cycles is reported. The LV fractional shortening percentage was calculated as $([$ LVEDD - LVESD]/LVEDD) $\times 100$.

Losartan studies. Losartan was administered via drinking water $(110 \mathrm{mg} / \mathrm{l})$, and estimated intake corresponded to $0.44 \mathrm{mg} / \mathrm{d}$. For studies that assessed whether losartan prevented the emergence of HCM, prehypertrophic mice received losartan for 2 weeks before CsA treatment was initiated. For studies that assessed reversal of HCM, the losartan dose was $0.6 \mathrm{~g} / 1$ (34).

Tgf $\beta$ NAb studies. Prehypertrophic mice received either high-dose Tgf- $\beta$ $\mathrm{NAb}(10 \mathrm{mg} / \mathrm{kg}$ body weight in PBS) or low-dose Tgf- $\beta \mathrm{NAb}(5 \mathrm{mg} / \mathrm{kg}$ body weight in PBS) (R\&D Systems) by intraperitoneal injection every 3 days for 2 weeks prior to CsA treatment. Data obtained from high and low doses were indistinguishable and are reported as combined. Control prehypertrophic mice were treated with rabbit IgG (R\&D Systems) at identical doses as those for Tgf- $\beta$ NAb for 2 weeks prior to CsA.

Myocyte and non-myocyte isolation. Cells were isolated from the mice after Langendorff heart preparation and enzymatic digestion, as described previously $(63,65)$. Following enzyme perfusion, ventricles were gently minced into small pieces and passed through a sterile pipette several times on the culture dish with transfer buffer. Cell suspensions were passed through a mesh filter into $50-\mathrm{ml}$ centrifuge tube and incubated for 15 minutes. Cells were pelleted and resuspended in gradient calcium loading buffers and sequentially transferred every 10 minutes to subsequent calcium loading buffers, using new sterile plastic pipettes to reduce cross-cell contamination. TRIzol reagent (Invitrogen) was added in the final myocyte pellet and total RNA was extracted according to manufacturer protocols. For isolation of non-myocyte cells, all supernatants from isolated cell solution and calcium loading buffers were collected in the same tube and centrifuged at $329 \mathrm{~g}$ for 12 minutes. The pellet was resuspended in DMEM with $10 \% \mathrm{FBS}$ and $1 \%$ penicillin-streptomycin and plated in sterile dishes $\left(37^{\circ} \mathrm{C}\right)$. After a 2 -hour incubation, cells attached to the dish were visible and rinsed with sterile PBS to remove nonadherent cells and debris. Attached cells were harvested and an aliquot was used for morphology and immunohistochemical staining, using vimentin and troponin I antibodies to identify non-myocyte cells and myocytes, respectively. The estimated cross-cell contamination was less than or equal to $10 \%$. Total RNA of non-myocyte cells was extracted from harvested cells using TRIzOL reagent (Invitrogen), as described above.

$D S A G E$ and real-time PCR analyses. Transcriptional profiling was performed using approximately $0.5 \mu \mathrm{g}$ RNA, pooled from total RNA isolated from cells from 4 male mice matched for age and treatment. DSAGE was performed as described previously (12) but adapted to sequence 21-bp NLAIII tags using an Illumina Genome Analyzer II. More than 2 million reads were obtained from RNA preparations derived from both myocytes and non-myocyte cells. Quantitative expression of genes was computed by summing the tag counts for all of the $3^{\prime}$ ends detected in the DSAGE library. The entire transcriptional profile, corresponding to approximately 200,000 distinct tags, was assigned to genes using the Harvard Research Computing Cluster, Orchestra. Using specific primers for Postn, Ctgf, Tgfb1, and Tgfb2 genes, RNA levels were validated by quantitative real-time PCR analysis using RNA isolated from hypertrophic and non-hypertrophic ventricles as described previously $(9,12)$.

GO. Functional annotation and GO term enrichment analyses were performed using the DAVID tool, as described previously $(22,23)$. We compared 1,317 RNAs that were differentially expressed $(P<0.001)$ in non-myocyte cells (identified by DSAGE; Supplemental Table 1) to 16,500 genes expressed in the mouse LV for level $3 \mathrm{GO}$ terms. GO terms that were overrepresented among these 1,317 genes reflect significant gene enrichment (Bonferronicorrected $P<0.05$; modified Fisher's exact test) and $\geq 1.5$-fold enrichment.

Quantification of myocardial fibrosis. Hearts were excised from isofluraneeuthanized mice, washed in PBS, fixed overnight in $4 \%$ paraformaldehyde, and embedded in paraffin as described previously $(18,66,67)$. After serial sectioning of hearts (apex to base) $9-15,5-\mu \mathrm{m}$ sections were stained with Masson trichrome. Fibrosis areas within sections were measured by 2 experienced observers blinded to genotypes, by visualizing blue-stained areas, exclusive of staining that colocalized with perivascular or intramural vascular structures, the endocardium, or LV trabeculae. Using ImageJ software (http://rsbweb.nih.gov/ij/), blue-stained areas and non-stained myocyte areas from each section were determined using color-based thresholding (68). The percentage of total fibrosis area was calculated as the summed blue-stained areas divided by total ventricular area, as described previously (18).

Immunohistochemical analyses. Cardiac tissues were harvested and processed as described above. Sections were deparaffinized in xylenes, rehydrated through ethanol gradient solutions to PBS, and permeabilized in $0.1 \%$ Tween in PBS. Heat-induced antigen retrieval was performed in citric acid buffer, $\mathrm{pH}$ 6.0, and/or target retrieval solution (Dako). Normal goat serum $(10 \%)$ and $1 \%$ BSA in PBS were used as blocking agents. Rabbit antiperiostin antibody (1:500; ref. 69), rat anti-Ki67 antibody (1:100, Dako), rabbit anti-fibroblast-specific protein 1 antibody (1:100, Dako), and FITCconjugated mouse anti- $\alpha$-smooth muscle actin antibody (1:1,000, SigmaAldrich) were used as primary antibodies. Sections were washed in PBS and then incubated with Alexa Fluor 488- or 594-conjugated secondary antibodies. Before slide mounting, sections were stained for highly glycosylated collagen that demarcated fibrosis $(70,71)$ using fluorescent-conjugated WGA (Invitrogen) and for cell nuclei using DAPI (Invitrogen). Negative controls were run in parallel using isotype-specific antibodies.

Cell proliferation. BrdU (Sigma-Aldrich) was injected daily into the peritoneum $(100 \mathrm{mg} / \mathrm{kg}$ body weight in PBS) for 3 days, with the last injection 2 hours prior to harvesting hearts. Hearts were fixed in $4 \%$ paraformaldehyde, paraffin embedded, and sectioned. BrdU-positive nuclei were detected with mouse monoclonal anti-BrdU primary antibody (Dako) and immunofluorescent staining as described above.

BrdU- or Ki67-labeled cells and DAPI-stained nuclei were counted in non-myocyte cells from $5-10$ fields ( $\times 400$ magnification) with focal fibrosis and/or expanded interstitium (identified by WGA staining) and areas with preserved myocardial architecture (e.g., absence of both focal fibrosis and expanded interstitium) in 9-15 sections per heart. Myocytes were identified by sarcomeres visualized with fluorescent microscopy. Cells without sarcomeres within interstitial regions were designated non-myocyte nuclei. Nuclei were quantified using ImageJ nucleus counter software (68). Percentages of proliferating cells were calculated as the number of positive BrdU- or Ki67labeled nuclei divided by the number of DAPI-stained nuclei. 
Western blots. LV tissue was dissected, washed in PBS, and homogenized in modified radioimmunoprecipitation assay buffer $(50 \mathrm{mM}$ Tris- $\mathrm{HCl}$, pH 7.4, $150 \mathrm{mM} \mathrm{NaCl}$, 1\% Nonidet P-40, 1 mM EDTA, 0.25\% sodium deoxycholate, $0.1 \%$ SDS, Protease Inhibitor Cocktail [Roche], and Halt Phosphatase Inhibitor Cocktail [Thermo Scientific]). Tissue lysates were incubated on ice for 30 minutes and clarified by centrifugation at $20817 \mathrm{~g}$ at $4^{\circ} \mathrm{C}$ for 20 minutes. Protein concentration was determined using the BCA Protein Assay Kit, according to the manufacturer's instructions (Thermo Scientific). Lysates were heated to $95^{\circ} \mathrm{C}$ in sample buffer $(62.5 \mathrm{mM}$ Tris-HCl, $\mathrm{pH} 6.8,10 \%$ glycerol, $2 \%$ SDS, $2.5 \% \beta$-mercaptoethanol, and $0.005 \%$ bromphenol blue) for 5 minutes. For immunoblotting, lysates were resolved by $4 \%-20 \%$ SDS-PAGE and transferred onto PVDF membrane (Thermo Scientific). Membranes were blocked with $5 \%$ nonfat dry milk in Tris-buffered saline/Tween 20 (TBS-T) for 1 hour at room temperature. Primary antibodies were diluted in $2.5 \%$ nonfat dried milk in TBS-T. Dilutions of periostin antibody (provided by S. Hoffman, Medical University of South Carolina) were 1:5,000, and dilutions of GAPDH antibody (Abcam) were $1: 10,000$. Both primary antibodies were incubated with membranes overnight at $4{ }^{\circ} \mathrm{C}$, and then membranes were washed in TBS-T and incubated with anti-rabbit IgG horseradish peroxidase-linked antibody (Santa Cruz Biotechnology Inc.) diluted in $2.5 \%$ nonfat dried milk in TBS-T for 1 hour at room temperature. After secondary antibody incubations, membranes were washed in TBS-T and visualized by using SuperSignal West Pico Chemiluminescent Substrate (Thermo Scientific).

Statistics. All data are expressed as mean \pm SD. The statistical significance of differences between experimental groups was determined using unpaired 2-tailed Student's $t$ test and Pearson's $\chi^{2}$ test. $P$ values of less than 0.05 are considered statistically significant.

\section{Acknowledgments}

This work was supported by grants from Deutsche Forschungsgemeinschaft and Deutsche Stiftung für Herzforschung (to J.P. Schmitt), HHMI (to C.E. Seidman and J.D. Molkentin), the Leducq Fondation (to R. Markwald, C.E. Seidman, and J.G. Seidman), NHLBI (to R. Markwald, C.E. Seidman, and J.G. Seidman), and NIH (to J.G. Seidman). R. Markwald, R. Norris, and S. Hoffman were supported by the following grants: NIH-NHLBI HL33756, NIH-NCRR COBRE P20RR016434, ARRA Administrative Supplement for Translational Research, NIH-NCRR COBRE P20RR021949, the Foundation Leducq (Paris, France) Transatlantic Mitral Network of Excellence Grant 07CVD04, and the National Science Foundation: EPS0902795. Their work was conducted in a facility constructed with support from NIH C06 RR018823 from the Extramural Research Facilities Program of the National Center for Research Resources.

Received for publication December 14, 2009, and accepted in revised form July 14, 2010.

Address correspondence to: J.G. Seidman, Department of Genetics, Harvard Medical School, 77 Avenue Louis Pasteur, NRB 256, Boston, Massachusetts 02115, USA. Phone: 617.432.7871; Fax: 617.432.7832; E-mail: seidman@genetics.med.harvard.edu.
1. Seidman JG, Seidman C. The genetic basis for cardiomyopathy: from mutation identification to mechanistic paradigms. Cell. 2001;104(4):557-567.

2. Maron BJ, Seidman JG, Seidman CE. Proposal for contemporary screening strategies in families with hypertrophic cardiomyopathy. J Am Coll Cardiol. 2004;44(11):2125-2132.

3. Maron BJ. Cardiology patient pages. Hypertrophic cardiomyopathy. Circulation. 2002;106(19):2419-2421.

4. Dhandapany PS, et al. A common MYBPC3 (cardiac myosin binding protein $\mathrm{C}$ ) variant associated with cardiomyopathies in South Asia. Nat Genet. 2009;41(2):187-191.

5. Maron BJ. Hypertrophic cardiomyopathy in China. Am J Cardiol. 2007;100(1):145-146.

6. Morita $\mathrm{H}$, et al. Single-gene mutations and increased left ventricular wall thickness in the community: the Framingham Heart Study. Circulation. 2006;113(23):2697-2705.

7. Tyska MJ, Hayes E, Giewat M, Seidman CE, Seidman JG, Warshaw DM. Single-molecule mechanics of R403Q cardiac myosin isolated from the mouse model of familial hypertrophic cardiomyopathy. Circ Res. 2000;86(7):737-744

8. Debold EP, et al. Hypertrophic and dilated cardiomyopathy mutations differentially affect the molecular force generation of mouse alpha-cardiac myosin in the laser trap assay. Am J Physiol Heart Circ Physiol. 2007;293(1):H284-H291.

9. Palmer BM, et al. Myofilament mechanical performance is enhanced by R403Q myosin in mouse myocardium independent of sex. Am J Physiol Heart Circ Physiol. 2008;294(4):H1939-H1947.

10. Georgakopoulos D, Christe ME, Giewat M, Seidman CM, Seidman JG, Kass DA. The pathogenesis of familial hypertrophic cardiomyopathy: early and evolving effects from an alpha-cardiac myosin heavy chain missense mutation. Nat Med. 1999;5(3):327-330.

11. Fatkin D, et al. An abnormal $\mathrm{Ca}(2+)$ response in mutant sarcomere protein-mediated familial hypertrophic cardiomyopathy. J Clin Invest. 2000;106(11):1351-1359.

12. Kim JB, et al. Polony multiplex analysis of gene expression (PMAGE) in mouse hypertrophic cardiomyopathy. Science. 2007;316(5830):1481-1484.

13. Weber KT. Monitoring tissue repair and fibrosis from a distance. Circulation. 1997;96(8):2488-2492.

14. Zeisberg EM, et al. Endothelial-to-mesenchyma transition contributes to cardiac fibrosis. Nat Med. 2007;13(8):952-961.

15. Wynn TA. Cellular and molecular mechanisms of fibrosis. J Pathol. 2008;214(2):199-210.

16. Moreo A, et al. Influence of myocardial fibrosis on left ventricular diastolic function: noninvasive assessment by cardiac magnetic resonance and echo. Circ Cardiovasc Imaging. 2009;2(6):437-443.

17. Geisterfer-Lowrance AA, et al. A mouse model of familial hypertrophic cardiomyopathy. Science. 1996;272(5262):731-734.

18 . Wolf CM, et al. Somatic events modify hypertrophic cardiomyopathy pathology and link hypertrophy to arrhythmia. Proc Natl Acad Sci U S A. 2005;102(50):18123-18128.

19. Tan LB, Jalil JE, Pick R, Janicki JS, Weber KT. Cardiac myocyte necrosis induced by angiotensin II. Circ Res. 1991;69(5):1185-1195.

20. Muskhelishvili L, Latendresse JR, Kodell RL, Henderson EB. Evaluation of cell proliferation in rat tissues with BrdU, PCNA, Ki-67(MIB-5) immunohistochemistry and in situ hybridization for histone mRNA. J Histochem Cytochem. 2003;51(12):1681-1688.

21. Keeling J, Herrera GA. Human matrix metalloproteinases: characteristics and pathologic role in altering mesangial homeostasis. Microsc Res Tech. 2008;71(5):371-379.

22. Huang da W, Sherman BT, Lempicki RA. Systematic and integrative analysis of large gene lists using DAVID bioinformatics resources. Nat Protoc. 2009;4(1):44-57.

23. Dennis G Jr, et al. DAVID: database for annotation, visualization, and integrated discovery. Genome Biol. 2003;4(5):P3.

24. Gerdes J, Lemke H, Baisch H, Wacker HH, Schwab $\mathrm{U}$, Stein H. Cell cycle analysis of a cell proliferation-associated human nuclear antigen defined by the monoclonal antibody Ki-67. J Immunol. 1984;133(4):1710-1715.

25. Gratzner HG. Monoclonal antibody to 5bromo- and 5-iododeoxyuridine: A new reagent for detection of DNA replication. Science. 1982;218(4571):474-475

26. Lorts A, Schwanekamp JA, Elrod JW, Sargent MA, Molkentin JD. Genetic manipulation of periostin expression in the heart does not affect myocyte content, cell cycle activity, or cardiac repair. Circ Res. 2009;104(1):e1-e7.

27. Soonpaa MH, Kim KK, Pajak L, Franklin M, Field LJ. Cardiomyocyte DNA synthesis and binucleation during murine development. Am J Physiol. 1996;271(5 pt 2):H2183-H2189.

28. Strutz F, et al. Identification and characterization of a fibroblast marker: FSP1. J Cell Biol. 1995;130(2):393-405.

29. Tomasek JJ, Gabbiani G, Hinz B, Chaponnier C, Brown RA. Myofibroblasts and mechano-regulation of connective tissue remodelling. Nat Rev Mol Cell Biol. 2002;3(5):349-363.

30. Schneider M, Hansen JL, Sheikh SP. S100A4: a common mediator of epithelial-mesenchymal transition, fibrosis and regeneration in diseases? J Mol Med. 2008;86(5):507-522.

31. Oka T, et al. Genetic manipulation of periostin expression reveals a role in cardiac hypertrophy and ventricular remodeling. Circ Res. 2007;101(3):313-321.

32. Porter KE, Turner NA. Cardiac fibroblasts: at the heart of myocardial remodeling. Pharmacol Ther. 2009;123(2):255-278.

33. Ling $\mathrm{H}$, et al. Therapeutic role of TGF-betaneutralizing antibody in mouse cyclosporin A nephropathy: morphologic improvement associated with functional preservation. J Am Soc Nephrol. 2003;14(2):377-388.

34. Habashi JP, et al. Losartan, an AT1 antagonist, prevents aortic aneurysm in a mouse model of Marfan syndrome. Science. 2006;312(5770):117-121.

35. Cohn RD, et al. Angiotensin II type 1 receptor blockade attenuates TGF-beta-induced failure of 
muscle regeneration in multiple myopathic states. Nat Med. 2007;13(2):204-210.

36. Lim DS, et al. Angiotensin II blockade reverses myocardial fibrosis in a transgenic mouse model of human hypertrophic cardiomyopathy. Circulation. 2001;103(6):789-791

37. O'Hanlon R, Pennell DJ. Cardiovascular magnetic resonance in the evaluation of hypertrophic and infiltrative cardiomyopathies. Heart Fail Clin. 2009;5(3):369-387, vi.

38. Menon SC, Eidem BW, Dearani JA, Ommen SR, Ackerman MJ, Miller D. Diastolic dysfunction and its histopathological correlation in obstructive hypertrophic cardiomyopathy in children and adolescents. J Am Soc Echocardiogr. 2009;22(12):1327-1334.

39. Esposito A, et al. Impaired left ventricular energy metabolism in patients with hypertrophic cardiomyopathy is related to the extension of fibrosis at delayed gadolinium-enhanced magnetic resonance imaging. Heart. 2009;95(3):228-233.

40. McLeod CJ, et al. Histologic characterization of hypertrophic cardiomyopathy with and without myofilament mutations. Am Heart J. 2009. 158(5):799-805.

41. Rubinshtein R, et al. Characteristics and clinical significance of late gadolinium enhancement by contrast-enhanced magnetic resonance imaging in patients with hypertrophic cardiomyopathy. Circ Heart Fail. 2010;3(1):51-58.

42. Maron MS, et al. The case for myocardial ischemia in hypertrophic cardiomyopathy. J Am Coll Cardiol. 2009;54(9):866-875.

43. Lombardi R, et al. Resolution of established cardiac hypertrophy and fibrosis and prevention of systolic dysfunction in a transgenic rabbit model of human cardiomyopathy through thiol-sensitive mechanisms. Circulation. 2009;119(10):1398-1407.

44. Ho CY, et al. Assessment of diastolic function with Doppler tissue imaging to predict genotype in preclinical hypertrophic cardiomyopathy. Circulation. 2002;105(25):2992-2997.

45. Okada H, Danoff TM, Kalluri R, Neilson EG. Early role of Fsp1 in epithelial-mesenchymal transformation. Am J Physiol. 1997;273(4 pt 2):F563-F574.

46. Endo J, et al. Bone marrow derived cells are involved in the pathogenesis of cardiac hypertrophy in response to pressure overload. Circulation.
2007;116(10):1176-1184.

47. Fujita J, et al. Administration of granulocyte colony-stimulating factor after myocardial infarction enhances the recruitment of hematopoietic stem cell-derived myofibroblasts and contributes to cardiac repair. Stem Cells. 2007;25(11):2750-2759.

48. Haudek SB, et al. Bone marrow-derived fibroblast precursors mediate ischemic cardiomyopathy in mice. Proc Natl Acad Sci US A. 2006;103(48):18284-18289.

49. Kuhn B, et al. Periostin induces proliferation of differentiated cardiomyocytes and promotes cardiac repair. Nat Med. 2007;13(8):962-969.

50. Visconti RP, Markwald RR. Recruitment of new cells into the postnatal heart: potential modification of phenotype by periostin. Ann N Y Acad Sci. 2006;1080:19-33.

51. Norris RA, et al. Periostin regulates atrioventricular valve maturation. Dev Biol. 2008;316(2):200-213.

52. Shimazaki M, et al. Periostin is essential for cardiac healing after acute myocardial infarction. J Exp Med. 2008;205(2):295-303.

53. Ruwhof C, van Wamel AE, Egas JM, van der Laarse A. Cyclic stretch induces the release of growth promoting factors from cultured neonatal cardiomyocytes and cardiac fibroblasts. Mol Cell Biochem 2000;208(1-2):89-98.

54. van Wamel AJ, Ruwhof C, van der Valk-Kokshoom LE, Schrier PI, van der Laarse A. The role of angiotensin II, endothelin-1 and transforming growth factor-beta as autocrine/paracrine mediators of stretch-induced cardiomyocyte hypertrophy. $\mathrm{Mol}$ Cell Biochem. 2001;218(1-2):113-124.

55. van Wamel AJ, Ruwhof C, van der Valk-Kokshoorn LJ, Schrier PI, van der Laarse A. Stretch-induced paracrine hypertrophic stimuli increase TGF-beta1 expression in cardiomyocytes. Mol Cell Biochem. 2002;236(1-2):147-153

56. Hinz B. Tissue stiffness, latent TGF-beta1 activation, and mechanical signal transduction: implications for the pathogenesis and treatment of fibrosis. Curr Rheumatol Rep. 2009;11(2):120-126.

57. Goodwin A, Jenkins G. Role of integrin-mediated TGFbeta activation in the pathogenesis of pulmonary fibrosis. Biochem Soc Trans. 2009;37(pt 4):849-854.

58. Moustakas A, Heldin $\mathrm{CH}$. The regulation of TGFbeta signal transduction. Development. 2009; 136(22):3699-3714
59. Renard M, et al. Altered TGFbeta signaling and cardiovascular manifestations in patients with autosomal recessive cutis laxa type I caused by fibulin- 4 deficiency. Eur J Hum Genet. 2010;18(8):895-901.

60. Abe M, Okada K, Matsumoto K. Clinical experience in treating hypertension with fixed-dose combination therapy: angiotensin II receptor blocker losartan plus hydrochlorothiazide. Expert Opin Drug Metab Toxicol. 2009;5(10):1285-1303.

61. Matt P, et al. Circulating transforming growth factor-beta in Marfan syndrome. Circulation. 2009;120(6):526-532.

62. Schmitt JP, et al. Cardiac myosin missense mutations cause dilated cardiomyopathy in mouse models and depress molecular motor function. Proc Natl Acad SciUS A. 2006;103(39):14525-14530.

63. Schmitt JP, et al. Dilated cardiomyopathy and heart failure caused by a mutation in phospholamban. Science. 2003;299(5611):1410-1413.

64. Norris RA, et al. Periostin regulates collagen fibrillogenesis and the biomechanical properties of connective tissues. J Cell Biochem. 2007;101(3):695-711.

65. Wolf CM, et al. Lamin A/C haploinsufficiency causes dilated cardiomyopathy and apoptosis-triggered cardiac conduction system disease. J Mol Cell Cardiol. 2008;44(2):293-303.

66. Arad M, et al. Transgenic mice overexpressing mutant PRKAG2 define the cause of Wolff-Parkinson-White syndrome in glycogen storage cardiomyopathy. Circulation. 2003;107(22):2850-2856.

67. Semsarian C, et al. The L-type calcium channel inhibitor diltiazem prevents cardiomyopathy in a mouse model. J Clin Invest. 2002;109(8):1013-1020.

68. Abramoff MD, Magelhaes PJ, Ram SJ. Image processing with ImageJ. Biophotonics Int. 2004;11(7):36-42.

69. Kruzynska-Frejtag A, et al. Periostin is expressed within the developing teeth at the sites of epithelial-mesenchymal interaction. Dev Dyn. 2004; 229(4):857-868.

70. Pandya K, Kim HS, Smithies O. Fibrosis, not cell size, delineates beta-myosin heavy chain reexpression during cardiac hypertrophy and normal aging in vivo. Proc Natl Acad Sci US A. 2006;103(45):16864-16869.

71. Parikka V, et al. Estrogen reduces the depth of resorption pits by disturbing the organic bone matrix degradation activity of mature osteoclasts. Endocrinology. 2001;142(12):5371-5378. 